\title{
ASSOCIATIONS OF BIOCHEMICAL CHANGES AND MATERNAL TRAITS WITH MUTATION 1843 (C $>$ T) IN THE RYR1 GENE AS A COMMON CAUSE FOR PORCINE STRESS SYNDROME
}

\author{
Popovski ZT ${ }^{1, *}$, Tanaskovska B ${ }^{1}$, Miskoska-Milevska E², Andonov $\mathrm{S}^{3}$, Domazetovska $\mathrm{S}^{4}$
}

\begin{abstract}
*Corresponding Author: Professor Zoran T. Popovski, Ph.D., Faculty of Agriculture and Food Sciences, Bld "Aleksandar Makedonski," bb PB 297, 1000 Skopje, Republic of Macedonia. Tel: +389-70-252-731. Fax: +389-2-3134-310. E-mail: zoran_popovski@yahoo.com
\end{abstract}

\begin{abstract}
Stress syndrome is usually caused by a mutation in the ryanodine receptor gene (ryrl) and it is widely studied in humans and swine populations. The protein product of this gene plays a crucial role in the regulation of calcium transport in muscle cells. A G>T mutation in the human ryrl gene, which results in the replacement of a conserved arginine at position 614 where a leucine occurs at the same position as the previously identified Arg $\rightarrow$ Cys mutation reported in all cases of porcine stress syndrome (PSS). Porcine stress syndrome affects biochemical pathways in stress-susceptible individuals during a stress episode and some biochemical parameters that were used as markers for diagnostic purposes. Also, PSS has remarkable influence on the maternal characteristics of sows. This study dealt with different genotypes for PSS and its association with possible biochemical changes and maternal traits of sows. Seventy-three reproductive sows genotyped for PSS by polymerase chain reaction-restriction fragment length polymorphism (PCR-RFLP) were included in this survey. Sixty of them were stress-free (NN), 11 were heterozygous carriers $(\mathrm{Nn})$ and two animals were homozygous (nn) for the $1843(\mathrm{C}>\mathrm{T})$ mutation. Significant differences in non stress induced animals with different PSS genotypes were found in the values of creatine phoshokinase (CPK), lactate
\end{abstract}

\footnotetext{
${ }^{1}$ Department of Biochemistry and Genetic Engineering, Faculty of Agriculture and Food Sciences, Skopje, Republic of Macedonia

${ }^{2}$ Food Department, Faculty of Agriculture and Food Sciences, Skopje, Republic of Macedonia

${ }^{3}$ Livestock Department, Faculty of Agriculture and Food Sciences, Skopje, Republic of Macedonia

${ }^{4}$ Faculty of Medicine, Institute of Clinical Biochemistry, Skopje, Republic of Macedonia
}

dehydrogenase (LDH), alkaline phosphatase (AP) and aspartate aminotransferase (AST). Regarding the maternal traits, our study showed that stress susceptible animals (nn) have an increased number of stillborn piglets and a reduced number of newborn piglets compared with heterozygous and normal animals.

Keywords: Biochemistry; Genotypes; Maternity; Porcine stress syndrome (PSS).

\section{INTRODUCTION}

Porcine stress syndrome (PSS) is a hypermetabolic and hypercontractile syndrome triggered by anesthesia or various stressors that cause a sustained increase in sarcoplasmic calcium ion $\left(\mathrm{Ca}^{2+}\right)$ [1]. The main consequence of PSS in humans and swine is the appearance of malignant hyperthermia (MH). Susceptibility to PSS is inherited as an autosomal dominant disease. Human $\mathrm{MH}$ is a lifethreatening, acute pharmacogenetic disorder of the skeletal muscle cells. Its manifestations are normally silent and only made evident when susceptible patients receive general anesthesia with volatile anesthetic agents or succinyldicholine [2].

The ryanodine receptor gene ( $r y r l)$ is the primary locus for stress susceptibility, but also other genes may be involved $[3,4]$. Predominantly, stress susceptibility in humans has been linked to the ryrl gene and four other loci related to skeletal muscle excitation contraction coupling [2]. Most of the families with a familial history of stress syndrome have linkage to one of 175 mutations within ryr 1 located on 19q13.1 [5]. Most frequent is a G $>$ T transition mutation that results in the replacement of a conserved arginine at position 614 by leucine. A similar mutation occurs at position 1843 $(\mathrm{C}>\mathrm{T})$ resulting in replacement of arginine by cystine at 
position 615 in the swine genome in the ryrl gene at locus 6p11-q21 [6]. Malignant hyperthermia occurs infrequently in humans (about one in 50,000), but PSS is common in pigs $[7,8]$. The similarity of the human and swine ryrl gene is $91.2 \%$. How this mutation affects the function in myotubes is not understood [9], but recent studies have shown that mutations in the ryrl gene alter bidirectional signalling between 6,7-dihydropyeridine reductase (DHPR) and ryrl, even in the absence of triggering agents [10].

Malignant hyperthermia exhibits a hypermetabolic response with the release of lactic acid, potassium, and proteins (e.g., myoglobin and enzymes) from muscle cells. Their release accompanied with massive increase of blood catecholamines can result in death [1]. The pathophysiology of the crisis involves an uncontrolled release of cytoplasmic free calcium from the sarcoplasmic reticulum, leading to activation of energy-producing biochemical pathways [3]. In individuals susceptible to stress, it is generally accepted that increased level of either sarcoplasmic or myofibrillar-free calcium is the biochemical cause of the syndrome [11]. Thus, the main biochemical expression of PSS is intracellular deficit of $\mathrm{Ca}^{2+}$ that is mainly stored in terminal cisternae of sarcoplasmic reticulum where it is bound to the calcium-binding protein calsequestrin [12].

Total plasma calcium concentrations increase during a PSS crisis. Sarcoplasmic proteins also leak from muscle fibers during an acute episode. For instance, it is well-known that myoglobin, which has a low molecular weight ( $c a$. 16,000 Da), leaks into the circulation, resulting in myoglobinemia [13].

The conversion of lactate, alanine and aspartate to glucose and oxidation of each to carbon dioxide $\left(\mathrm{CO}_{2}\right)$, are processes that can be influenced by PSS [14]. Also, the stress causes a depletion of adenosine triphosphate (ATP) and extensive glycolysis in muscles [15], which can affect the activity of alkaline phosphatase (AP) responsible for removing the phosphate groups from several molecules, including nucleotides. Another interesting parameter closely related to ATP conversion is creatine phospho-kinase (CPK) that is associated with PSS [16]. It was suggested that fewer proteins are catabolized during the alanine cycle in stress-susceptible pigs; thus, total proteins were also included in this study [14]. Regarding that fact the accumulation of degradation metabolites (creatinine and bilirubin) generated by increased metabolic activity could be expected as possible biochemical markers of $\mathrm{MH}$.

The effects of PSS have been investigated on maternal performances. Heterozygous PSS (Nn) females farrowed more pigs in first pig birth than normal (NN) and homozy- gous (nn) females. The proportion of pigs born alive that survived was not different between females of differing PSS genotypes. Normal and Nn females had nearly identical adjusted number of live-born piglets [17]. The goal of this study was to determine the differences in nine biochemical parameters associated with PSS genotypes, and matching the PSS genotype with maternal traits in selected sows.

\section{MATERIALS AND METHODS}

Blood was taken from 73 randomly chosen sows that were not exposed to stress. After the centrifugation step $(1000 \times \mathrm{g}$ for $10 \mathrm{~min}$. at room temperature), the plasma samples underwent further biochemical analyses, while the leucocytes served for DNA extraction. DNA extraction from leucocytes was done using a DNA purification kit (Cat. \#A1125; Promega, Madison, WI, USA), according to the manufacturer's instructions.

Genotyping of PSS was performed using polymerase chain reaction-restriction fragment length polymorphism (PCR-RFLP) by digestion of the amplified part of the $r y r 1$ gene where the common $1843(\mathrm{C}>\mathrm{T})$ mutation occurs by digestion with $H$ haI restriction endonuclease, as previously described [18]. Biochemical analyses of nine biochemical parameters [bilirubin, $\mathrm{Ca}^{2+}$, creatinine, total protein, AP, aspartate aminotransferase (AST), alanine aminotransferase (ALT), CPK and lactate dehydrogenase (LDH)], were determined using an automatic analyzer (Cobas-Integra 700; Roche Diagnostics, Indianapolis, IN, USA).

Quantitative records on newborn, stillborn and weaned piglets (piglets that became independent) required for the statistical analyses were obtained from the data kept on the farms. Statistical analysis for genotype distribution and allele frequencies were determined by individual and allele counting. For the quantitative parameters and productive traits, descriptive statistical parameters (mean, minimum, maximum and mean standard error (MSE) were calculated. Later, the differences in the genotypes were tested with the Student $t$-test. All statistical evaluations were performed using the Statistical Package for the Social Sciences (SPSS), version 6.1 for Windows Student Version (SPSS Inc, Chicago, IL, USA; 1994).

\section{RESULTS}

An experiment was conducted with sows genotyped for PSS using DNA based methods. Using a PCR-RFLP approach, we determined the genotypes for PSS in 73 DNA samples, identifying 60 stress-free animals (NN), 11 
heterozygots $(\mathrm{Nn})$ and two homozygous stress-susceptible animals (nn). Allele frequency of the $\mathrm{N}$ and $\mathrm{n}$ alleles was 0.897 and 0.103 , respectively. The PCR-RFLP characterization of PSS is shown in Figure 1.

The results from genotyping were matched with values of nine biochemical parameters that were examined as possible predictors of PSS susceptibility in non-stress induced animals (Table 1). The study also explored the relevance of different biochemical parameters that could be used as possible biochemical markers for PSS susceptibility. Maternity traits matched with the genotype for PSS are shown in Table 2.

\section{DISCUSSION}

We did not find a significant correlation between the level of $\mathrm{Ca}^{2+}$ and stress susceptibility $[12,19]$. The values of plasma $\mathrm{Ca}^{2+}$ showed no significant differences among

Table 1. Biochemical data of plasma samples from animals with different porcine stress syndrome genotypes.

\begin{tabular}{|l|r|r|r|r|c|}
\hline Biochemical Parameter & \multicolumn{2}{l|}{ Genotype } & Reference Values $^{\mathrm{a}}$ & $\boldsymbol{t}_{\text {Value }}$ \\
\hline & $\mathrm{NN}$ & $\mathrm{Nn}$ & $\mathrm{nn}$ & & \\
\hline $\mathrm{Ca}^{2+}(\mu \mathrm{mol} / \mathrm{L})$ & 2.62 & 2.68 & 2.71 & $2.50-2.95$ & $1.14^{\mathrm{b}}$ \\
\hline Creatinine $(\mu \mathrm{mol} / \mathrm{L})$ & 142.10 & 157.30 & 174.60 & $88.40-265.20$ & $9.97^{\mathrm{c}}$ \\
\hline Total proteins $(\mathrm{g} / \mathrm{L})$ & 72.40 & 75.70 & 74.90 & $68.00-89.00$ & $1.42^{\mathrm{b}}$ \\
\hline Bilirubin $(\mu \mathrm{mol} / \mathrm{L})$ & 1.65 & 2.54 & 4.12 & $0.00-12.00$ & $12.79^{\mathrm{c}}$ \\
\hline AP $(\mathrm{U} / \mathrm{L})$ & 21.80 & 45.30 & 62.40 & $9.00-70.00$ & $14.55^{\mathrm{c}}$ \\
\hline AST $(\mathrm{U} / \mathrm{L})$ & 29.20 & 58.30 & 125.50 & $17.00-45.00$ & $16.32^{\mathrm{c}}$ \\
\hline ALT $(\mathrm{U} / \mathrm{L})$ & 35.30 & 51.70 & 48.20 & $9.00-60.00$ & $9.14^{\mathrm{b}}$ \\
\hline LDH (U/L & 398.00 & 655.00 & 894.00 & $159.00-475.00$ & $17.02^{\mathrm{c}}$ \\
\hline CPK (U/L) & 276.00 & 591.00 & 764.00 & $67.00-489.00$ & $15.29^{\mathrm{c}}$ \\
\hline
\end{tabular}

NN: stress-free; Nn: heterozygous carrier; nn: homozygous carrier; $\mathrm{Ca}^{2+}$ : calcium ion; AP: alkaline phosphatase; AST: aspartate aminotransferase; ALT: alanine aminotransferase; LDH: lactate dehydrogenase; CPK: creatine phosphokinase.

a Reference values from the Research Animal Resources, University of Minnesota, Minneapolis, MN, USA (http:// www.ahc.umn.edu/rar/ refvalues.htm).

b A $p$ value of $>0.05$ was not considered to be significant.

c A $p$ value of $<0.05$ was considered to be significant.

Table 2. Association of the porcine stress syndrome genotype with maternal traits (newborn, stillborn and weaned piglets).

\begin{tabular}{|c|c|c|c|}
\hline \begin{tabular}{|l|} 
PSS \\
Genotype
\end{tabular} & \multicolumn{2}{|c|}{ Newborn Piglets } & $t$ Value \\
\hline \multirow[t]{2}{*}{\begin{tabular}{|l|}
$\mathrm{NN}$ \\
$\mathrm{Nn}$ \\
$\mathrm{nn}$ \\
\end{tabular}} & $\begin{array}{l}10.92 \\
11.73 \\
11.50 \\
\end{array}$ & \begin{tabular}{|l}
0.22 \\
0.52 \\
1.50 \\
\end{tabular} & $2.59^{\mathrm{a}}$ \\
\hline & \multicolumn{2}{|c|}{ Stillborn Piglets } & \\
\hline \multirow[t]{2}{*}{$\begin{array}{l}\mathrm{NN} \\
\mathrm{Nn} \\
\mathrm{nn}\end{array}$} & $\begin{array}{l}0.15 \\
0.09 \\
1.5 \\
\end{array}$ & \begin{tabular}{|l}
0.06 \\
0.09 \\
0.50 \\
\end{tabular} & $2.53^{\mathrm{a}}$ \\
\hline & \multicolumn{2}{|c|}{ Weaned Piglets } & \\
\hline $\begin{array}{l}\mathrm{NN} \\
\mathrm{Nn} \\
\mathrm{nn}\end{array}$ & $\begin{array}{l}8.20 \\
9.00 \\
7.50\end{array}$ & $\begin{array}{l}0.19 \\
0.46 \\
0.50\end{array}$ & $0.05^{\mathrm{b}}$ \\
\hline
\end{tabular}

NN: stress-free; Nn: heterozygous carrier; nn: homozygous carrier.

a A $p$ value of $<0.05$ was considered to be significant.

b A $p$ value of $>0.05$ was not considered to be significant.

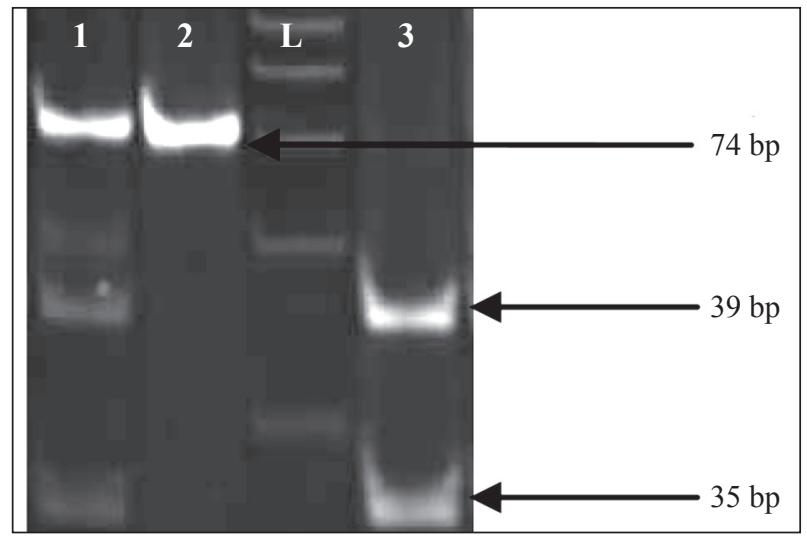

Figure 1. Thirteen percent polyacrylamide gel electrophoresis (PAGE) for PSS genotyping of the digested fragment of interest from the ryrl gene was done by RFLP using the $H h a \mathrm{I}$ restriction enzyme.

Lane 1: heterozygous (Nn genotype);

lane 2: homozygous (nn genotype); L: low range DNA ladder; lane 3: normal (NN genotype). 
the different PSS genotypes. All values for concentrations of $\mathrm{Ca}^{2+}$ were in the reference range. The biochemical data for total protein and ALT did not show significant association with the PSS genotypes.

The potential link between creatinine and bilirubin values with the PSS genotype has been previously presented [20]. The levels of creatinine, bilirubin and AP were in the frame of their reference ranges although the PSS-susceptible animals had higher values of creatinine, bilirubin and AP compared to those from stress-free and heterozygous animals. Nevertheless, the differences in the three groups of animals in some parameters were highly significant. Taking into account the role of AP in energy metabolism, creatinine as a final product of increased energy level and the releasing of myoglobin as one of the bilirubin precursors, those differences are explainable.

Lactate dehydrogenase was used as a biochemical marker for the identification of stress susceptible animals before development of molecular tools $[12,16]$. Our data confirmed that only the values of the enzyme from non induced stress-free animals (398.00 U/L) were in the frame of reference values, while the values of heterozygous $(\mathrm{Nn})$ animals were slightly out of that range $(655.00 \mathrm{U} / \mathrm{L})$. The values of stress-susceptible animals were 2-fold higher (894.00 U/L) than the maximum values of reference range (159.00-475.0 U/L) $(p<0.01)$. These data were consistent with the role of LDH in the metabolism of glucose in anaerobic glycolysis in humans [20]. The possible reason for that is the fact that even non induced stress is a reason for a slower rate of lactate and $\mathrm{CO}_{2}$ production from glucose, so the enzyme is accumulated in plasma [21].

Creatine phosphokinase was reported to be affected in PSS animals [21]. Our results showed that the values of the enzyme from stress-free animals (276.00 U/L) were within the normal range, the CPK values from the heterozygous pigs (591.00 U/L) were out of range, and the values of stress-susceptible animals were higher (764.00 $\mathrm{U} / \mathrm{L}$ ) than the maximum values of the reference range. Those differences matched with the PSS genotype were highly significant $(p<0.01)$. The mechanism of CPK activity is in energy metabolism and it is highly released by the stress susceptible animals. In the human population, up to $70.0 \%$ of stress susceptible subjects show increased muscle-specific CPK activity in plasma [22].

Deviation of AST values were observed in the animals with the different PSS genotype. We observed the highest deviation between the values we measured and the reference values. Only the data of stress-free animals (29.20 $\mathrm{U} / \mathrm{L}$ ) were in the frame of reference values, the values of heterozygous animals were higher $(58.30 \mathrm{U} / \mathrm{L})$, while the values of the homozygous animals $(125.50 \mathrm{U} / \mathrm{L})$ were 3 -fold higher than those in the reference range (17.00$45.00 \mathrm{U} / \mathrm{L})(p<0.01)$. This is the first published evidence about a possible association between AST and PSS.

Regarding maternal traits, we found that the heterozygous PSS sows with genotype $\mathrm{Nn}$ expresses the best reproductive ability, the highest number of newborn and the lowest number of stillborn piglets compared with nor$\mathrm{mal}(\mathrm{NN})$ and stress susceptible sows $(\mathrm{nn})(p<0.05)$. Also, in the Nn genotype, the number of weaned piglets was the highest compared with the other genotypes ( $\mathrm{NN}$ and $\mathrm{nn}$ ), but these differences were not statistically significant $(p>0.05)$. The lowest reproductive ability was observed in the nn genotype, with the lowest number of newborn, the highest number of stillborn and the lowest number of weaned piglets. It is important to point out that the nn category was represented by a limited number of samples, and therefore, this might be due to a sampling effect. There is no data about the association of maternal traits with genotype for stress syndrome in humans, bearing in mind that the same mutation occurs in the ryrl gene in the human and swine genome.

\section{ACKNOWLEDGMENTS}

The authors would like to express special respect to the late Academician Georgi D. Efremov who was supporting this research.

Declaration of Interest. The authors report no conflicts of interest. The authors alone are responsible for the content and writing of this article.

\section{REFERENCES}

1. O'Brien PJ, Klip A, Britt BA, Kalow BI. Malignant hyperthermia susceptibility: Biochemical basis for patho-genesis and diagnosis. Can J Vet Res. 1990; 54: 83-92.

2. Pessah NI, Allen DP. Malignant hyperthermia. Best Pract Res Clin Anaesth. 2001; 15(2): 277-228.

3. Ali ZS, Taguchi A, Rosenberg H. Malignant hyperthermia. Clin Anaesth. 2003; 17(3): 519-533.

4. Robinson R, Hopkins P, Carsana A, Gilly H, Halsall J, Heytens L, et al. Several interacting genes influence the malignant hyperthermia phenotype. Hum Genet. 2003; 112(2): 217-218. 
5. Robinson R, Carpenter D, Shaw MA, Halsall J, Hopkins P. Mutations in RYR1 in malignant hyperthermia and central core disease. Hum Mutat. 2006; 27(10): 977-989.

6. Quane KA, Ording H, Keating KE, Manning BM, Heine R, Bendixen D, et al. Detection of a novel mutation at amino acid position 614 in the ryanodine receptor in malignant hyperthermia. Br J Anaesth. 1997; 79(3): 332-337.

7. Wu S, Ibarra MC, Malicdan MC, Murayama K, Ichihara Y, et al. Central core disease is due to RYR1 mutations in more than $90 \%$ of patients. Brain. 2006; 129(Pt 6): 1470-1480.

8. Rosenborg H, Davis M, James D, Pollock D, Stowel K. Malignant hyperthermia. Orphanet J Rare Dis. 2007; 2: 21. doi: 10.1186/1750-1172-2-21.

9. Bannister RA, Estève E, Eltit JM, Pessah IN, Allen PD, López JR, et al. A malignant hyperthermia-inducing mutation in RYR1 (R163C): Consequent alterations in the functional properties of DHPR channels. J Gen Physiol. 2010; 135(6): 629-640.

10. Feng W, Barrientos G, Cherednichenko G, Yang T, Padilla T, Truong K, et al. Functional and biochemical properties of ryanodine receptor type 1 channels from heterozygous R163C malignant hyperthermiasusceptible mice. Mol Pharmacol. 2011; 79(3): 420 431.

11. Eltit JM, Yang T, Li H, Molinski TF, Pessah IN, Allen $\mathrm{PD}$, et al. RyR1-mediated $\mathrm{Ca}^{2+}$ leak and $\mathrm{Ca}^{2+}$ entry determine resting intracellular $\mathrm{Ca}^{2+}$ in skeletal myotubes. J Biol Chem. 2010; 285(18): 13781-13787.

12. Schmidt GR, Kastenschmidt LL, Cassens RG, Briskey EJ. Serum enzyme and electrolyte levels of stress resistant Chester White pigs and stress susceptible Poland China pigs. J Anim Sci. 1970; 31(6): 1168-1171.

13. Heffron J. Malignant hyperthermia: Biochemical aspects of the acute episode. Br J Anaesth. 1988; 60: 274-278.
14. Darrah PS, DiMaeco NM, Beitz DC, Topel DG. Conversion of alanine, aspartate and lactate to glucose and $\mathrm{CO} 2$ in liver from stress-susceptible and stressresistant pigs. J Nutr. 1979; 109(8): 1464-1468.

15. McLaughlin JV, Mothermill C. Halothane-induced rigidity and associated glycolytic and energy phosphate changes in red and white fibres of skeletal muscle of pig. J Comp Pathol. 1976; 86(3): 465-476.

16. Kruff B, Frahm K. Use of the creatine kinase test in piglet. Pig News and Information. 1985; 6(2): 1-5.

17. Stalder KJ. Effects of porcine stress syndrome genotype on maternal traits in swine. 1995. Ph.D. Thesis. Iowa State University, Ames, IA, USA.

18. Fujii J, Otsu K, Zorzato F, de Leon S, Khanna VK, Weiler JE. Identification of a mutation in porcine ryanodine receptor associated with malignant hyperthermia. Science. 1991; 253(5018): 448-451

19. Nelson TE, Jones EW, Henrickson RL, Falk SN, Kerr DD.: Porcine malignant hyperthermia. Observation on the occurrence of pale, soft and excudative musculature among susceptable pigs. J Vet Res. 1974; 35(3): 347-350.

20. Schaefer AL, Doornenbal H, Sather AP, Tong AKW, Jones SDM, Murray AC. The use of blood serum components in the identification of stress-susceptible and carrier pigs. Can J Anim Sci. 1990; 70: 845-855.

21. Ellis FR, Heffron JJA. Clinical and biochemical aspects of malignant hyperpyrexia. In: Atkinson RS, Adams AP, Eds. Recent Advances in Anesthesia and Analgesia. Edinburgh, UK: Churchill-Livingstone. 1985: 173-207.

22. Mabry JW, Christian LL, Kuhlers DL, Rasmusen BA. Prediction of susceptibility to the porcine stress syndrome. J Hered. 1983; 74(1): 23-26. 
